secondary effects, the bombardment can in several ways reasonably account for the observed phenomena connected with the earth light.

The Minor Planer I9II M.T.-.-When the minor planet I9II M.T. was discovered by Dr. Palisa, its direct motion suggested proximity to the earth, which might prove useful in parallax determinations. In No. 4573 of the Astronomische Nachrichten Dr. Palisa now gives elements, calculated by Messrs. Haynes and Pitman under Prof. Leuschner, which give the perihelion distance as $I \cdot 1273$ or $I \cdot I 643$, and the aphelion distance as 2.8629 or 2.5043 ; both sets of elements would probably be modified by further investigations, but the former appears to fit better the observations yet compared with it.

\section{THE ROYAL OBSERVATORY, GREENWICH.}

' HE annual visitation of the Royal Observatory took place on Saturday last, June I, when the Astronomer Royal presented to the Board of Visitors his report of the work done during the year ended May ro.

Many of the instruments were opened up for inspection, with assistants in charge to explain the many wonderful devices which are an essential part of the equipment of a great observatory of the present day. Visitors were greatly attracted by a new feature, the floating zenith telescope designed by the late Mr. Bryan Cookson, and lent to the observatory by the Cambridge Observatory authorities for a period of seven years. Similar to an ordinary zenith telescope in principle, the V's which carry the vertical telescope are carried by an iron ring floated on mercury, so that, with the two axes properly adjusted, verticality is automatically secured. Observations of pairs of stars by Talcott's method are being made to determine the variation of latitude and the aberration constant, and by combining the results for several years it is hoped to secure a very satisfactory determination of the aberration. This instrument replaces the old reflex zenith tube, which is incapable of giving the accuracy now required.

The fine summer enjoyed last year allowed the meridian observations of stars between $24^{\circ}$ and $32^{\circ}$ north declination, begun in I906, to make good progress, but the part of $2 h$. to $6 h$. R.A. is yet somewhat under-observed. During the twelve months nearly I4, Ooo transits were observed with the transit circle, besides the usual observations of nadir and level. From the I9Io observations, using the Pulkowa refractions, $38^{\circ} 3 \mathrm{I}^{\prime} 2 \mathrm{I} \cdot 83^{\prime \prime}$ was derived as the value of the colatitude, and the reduction of the observations of the sun gives a correction to the tabular value of the obliquity of the ecliptic of $+0.07^{\prime \prime}$. From the observations of the moon's limbs and the crater Mösting A, with the transit circle and altazimuth, the mean error of the moon's tabular place for I9 Io was $-0.537 \mathrm{~s}$. in R.A. and +0.32" in declination.

An investigation of the large discordance between north polar distances given by altazimuth in reversed positions points to faults in the eye end of the instrument, and this is being replaced by a new part. At the same time, a travelling-wire micrometer is to be introduced for observing R.A. and a printing micrometer for the zenith distances.

More than 700 observations of double stars, mostly pairs showing relative motion, were made with the 28 -in. refractor, nearly 300 of the observed pairs being separated by less than $I \cdot 0^{\prime \prime}$. The 26 -in. refractor, carried with the $30-i n$. reflector and the 6-in. Franklin-Adams lens on the Thompson equatorial, is being devoted to the determination of the parallaxes of stars in the Greenwich Astrographic Zone, photographs on the same plate being made at intervals of six months of all stars showing large proper motions. For this purpose an attempt was made to secure a better adjustment of the crown and flint components of the objective, to give greater accuracy, and it has been found necessary to order a new cell, carrying necessary adjustments, for the crown lens.

The work, with the $30-i n$. reflector, of securing photographic standards for the magnitudes of the stars counted on the Franklin-Adams plates, is delayed by the scarcity of nights at Greenwich on which the transparency of the sky is the same at the pole as at a similar altitude in the south. Variations of focus when the mirror was directed to different parts of the sky were also troublesome, but it is hoped to eliminate this trouble by using a subsidiary device for examining visually the focus. Among the interesting exhibits displayed on Saturday was a series of photographs taken with this instrument on October II, IgII, to locate the new minor planet M.T., believed to be very near to the earth. At first the examination of these plates failed to reveal the object, but later, when further data were received, images believed to be of the planet were found on three plates.

The Franklin-Adams 6-in. lens is used for determining photographic magnitudes of bright stars in the Greenwich zone, all of which can be covered by eighty-four fields; of these, fifty-five have been photographed and forty-one of the plates measured. A $30^{\circ}$ prism placed in front of this lens enabled photographs of the spectrum of Nova Geminorum (2) to be taken on several dates. Some of these exhibited on Saturday show excellent definition and great changes in the general nature of the spectrum, although the dispersion is small. The changes of magnitude of the nova were shown by photographs taken with the astrographic equatorial having a coarse wire grating placed in front of the object glass. With a grating made of $\mathrm{x} \cdot 6_{5} \mathrm{~mm}$. wire, with spaces from centre to centre of $5 \mathrm{~mm}$., the first diffraction images were sensibly round, and differed from the primary image by nearly two magnitudes.

Photographs of the sun were secured on 256 days, as against 182 days in the previous twelve months. Part of this increase was due to a greater amount of bright sunshine received and part due to an arrangement whereby work is commenced at $7 \mathrm{a.m}$. in the summer. The series of photographs for Igi $\mathrm{I}$ is complete except for January $\mathrm{I}$, on which date no photograph appears to have been taken at any of the four contributing observatories. All the evidence points to the present epoch as one of minimum solar activity, and advantage was taken of the lull to discuss the thirty-eight years' observations now available for determining the position of the sun's axis. The result shows that Carrington's position requires but a very small correction.

Two observers are going from Greenwich to Cruzeiro (lat. $22^{\circ} 39^{\prime} \mathrm{S}$., long. $44^{\circ} 58^{\prime} \mathrm{W}$.) to observe the Brazilian eclipse of the sun on October Io. Their equipment will include the Thompson 9-in. coronagraph and a quartz spectrograph especially fitted for recording the extreme ultra-violet part of the chromospheric spectrum.

Magnetic observations were carried out as usual, and showed that in IqII there were no days of "great" magnetic disturbance. For I9II the elements determined were :-

$$
\begin{aligned}
& \text { Mean declination } \quad \ldots \quad \quad \ldots \quad 15^{\circ} 33^{\circ} \mathrm{o}^{\prime} \mathrm{W} \text {. } \\
& \text {,, horizontal force .. } 0.18529 \text { (in C.G.S. units) } \\
& , \text { dip (with } 3 \text {-in. needles) } 66^{\circ} 52^{\prime} 6^{\prime \prime}
\end{aligned}
$$


In future, the Royal Observatory is to perform part of the work hitherto done by the Compass Branch of the Hydrographic Department. After I9I2 the observatory will prepare the declination charts, and will also collect the data available from land stations; the observations made on board ships will be collected and reduced by the Compass Branch and forwarded to Greenwich for incorporation in the charts. Additional responsibility is placed on the Astronomer Royal in the chronometer department also, and in future permission to submit chronometers and watches for the annual trials must be addressed to him directly.

Some interesting experiments were carried out on the effect of a magnetic field on the rates of chronometers and watches, and the results are soon to be published in the Monthly Notices (R.A.S.).

The chief feature of the meteorology of the twelve months was the breaking of several records, but details regarding these have already appeared in our notes columns.

\section{EIGHTEENTH INTERNATIONAL CON- GRESS OF AMERICANISTS.}

THERE have been eighteen sessions of the International Congress of Americanists, but this is the first time that a meeting has taken place in the British Isles, though six years ago an enjoyable meeting was held in Quebec. Although some very good work has been done in the past on the archæology of Central America and Peru by several Englishmen, there are at the present day very few students of American ethnology, linguistics, or archæology in this country-indeed, it may be said that the number of those who pay any attention to these subjects is also small, and it is to be hoped that the visit of the congress will do something to kindle an interest in the past and present history of the American aborigines.

The congress was invited to London by the Royal Anthropological Institute, on which body has fallen the duty of making the necessary arrangements. H.R.H. the Duke of Connaught kindly consented to be the patron, the services of our veteran Americanist, Sir Clements R. Markham, were fortunately secured as president, Dr. A. P. Maudslay was chairman of the organising committee, Sir R. Biddulph Martin and the late Mr. J. Gray were the treasurers, and Dr. F. C. A. Sarg and Miss A. C. Breton the secretaries. The chief work of organisation was undertaken by Miss Breton, and the success of the meeting was mainly due to her untiring energy and her personal knowledge of the delegates. Owing to the courtesy of the University of London the meetings were held at the Imperial Institute from May 27 to June I.

The programme consisted of the usual business meetings, papers, and discussions; Sir Richard and Lady Martin gave a reception on May 28, the president and committee received the congress at the Natural History Museum on May 29, and a dinner was given to the delegates on May 30. A visit was paid to the American collections in the British Museum, there were excursions to Cambridge and Oxford, and arrangements were made for a visit to the Blackmore Museum at Salisbury, and to Stonehenge and other places. A valuable feature of the congress was the exhibition arranged by Dr. Maudslay; it contained a large number of beautiful photographs of monuments investigated by him at Quiriqua, Tikal, Chichen Itza, Palenque, and Copan. Miss No. 2223 , VOL. 89]
Breton showed some of her masterly paintings of pottery and copies of frescoes, those from Acanceh, Yucatan, being of especial value, as the originals are now destroyed. Mrs. Zelia Nuttall exhibited a collection of photographs of documents and maps connected with Sir Francis Drake's last voyage. Mr. J. Cooper Clark lent a number of embroidered cloths from Mexico and Guatemala. Sir Clements Markham and others showed a number of antiquities, stone implements, pottery, and the like. Dr. A. V. Frič had a small ethnological collection from Gran Chaco. A very interesting series of paintings was exhibited by Dr. F. Heger, director of the Vienna Museum, which represent the mixture of races in Mexico; the subject of each picture is a father, mother, and child. The parents belong to different races or mixed breeds, and the progeny generally resemble one parent more than the other; each picture has an explanatory legend, and the whole series constituted a valuable demonstration in miscegenation.

The large number of the papers presented necessitated the holding of simultaneous sections, and the papers were grouped as follows:-

Palaeo-anthropology.-Dr. C. Peabody directed attention to the archæological importance of the recent work of $\mathrm{T}$. Volk in the gravels at Trenton, New Jersey. Dr. Ambrosetti exhibited a fossil skull and femur from Argentina; in the discussion it was pointed out that the skull was of the ordinary Indian type, with a slight amount of artificial deformation, the mineralisation was no criterion of age, and the position in which it was found did not prove a high antiquity. Dr. Hrdlička made an admirable report on ancient man in South America, in which he showed that there is no evidence of any extinct race of man that differs from recent man, and that proof is lacking of geological antiquity for man in South as well as in North America; he paid a high tribute to the zeal and honesty of the late Prof. Ameghino, but was unable to accept his conclusions. Miss Breton showed a photograph of an implement of Palæolithic type from the coast of Peru, and the question of a Palæolithic age in America was discussed by Dr. Capitan.

Physical Anthropology.-Dr. J. C. Tello demonstrated by means of lantern-slides the many methods of trephining practised by the ancient Peruvians; Dr. Hrdlička discussed the ethnic nature and probable origin of the American aborigines, in which he supported the generally recognised view of a sole Asiatic origin for them. A paper on Bolivian anthropology was contributed by Dr. Chervin.

Linguistics.-Dr. Waldemar Jochelson stated that the Aleut language is of Eskimo origin. W. Thalbitzer identified four Skræling words in Eirik the Red's saga as Eskimo, from which he inferred that the Eskimo probably peopled parts of Newfoundland in the eleventh century. Dr. F. Boas discussed the morphology and phonetics of the Mexican language. Dr. K. T. Preuss showed that the hitherto unstudied language of the Cora is structurally related to the Nahuatl. Among other contributions was one by Dr. S. A. Lafone Quevedo on the pronominal classification of certain South American Indian languages, and one by Prof. J. F. Oliveira on the language of the Cherentes of Central Brazil, a very primitive people.

A large number of papers dealt with the Ethnology and Archaeology, among which may be mentioned Prof. G. G. MacCurdy on shell gorgets from Missouri. Dr. Preuss indicated that thoughts and words are the intrinsically effectual part of the ceremonies and magic arts of the Cora Indians; the leaders of the ceremonies are called "thinkers"-they 